\title{
Effects of Geometry, Triggering and Foam-Filling on Crashworthiness Behaviour of a Cylindrical Composite Crash Box
}

\author{
M. Jahani, H. Beheshti* and M. Heidari-Rarani \\ Department of Mechanical Engineering, Faculty of Engineering, \\ University of Isfahan, 81746-73441, Isfahan, Iran \\ "Email: Hamid.beheshti@eng.ui.ac.ir
}

\begin{abstract}
Crash boxes play an important role in different industries as energy absorbers to reduce damage of accidents. An ideal crash box has lower maximum force and higher energy absorption. The aim of this study is to investigate the effect of various parameters such as geometry (diameter and thickness), triggering and filling with polymeric foam on axial crash behaviour of a composite cylindrical cash box. To this end, a composite crash box is modelled in a commercial finite element software, Abaqus, utilising the Hashin failure criterion to predict damage initiation. Linking damage initiation with material degradation rules provides the capability for damage evolution prediction on the basis of fracture energy of different failure modes. A new parameter $(\beta)$ is defined to study the performance of a crash box with different geometries, triggers and foam-filling. The results show that three different triggering geometries (chamfer, fillet, and tulip) decrease the maximum load about 7-33\%, and improved energy absorption about 40-86\% compared to the crash box without trigger. Filling a triggered crash box with polymeric foam also improves energy absorption about 20\%. Applying both triggering and foamfilling simultaneously on a crash box has a complementary role to receive a better performance.
\end{abstract}

Keywords: Composite crash box, finite element method, trigger, polymeric foam.

\section{INTRODUCTION}

The traffic accidents are one of the most important death causes in the different countries. Therefore, reducing damage of traffic accidents to passengers has been put on the agenda for the world by international organizations, according to "global status report on road safety 2015" of World Health Organization (WHO) [1]. Crash box is one of the most important parts in aeronautic and automotive vehicles as a crash energy absorber. In some industries such as automotive, in addition to energy absorption, low maximum load roles as an important factor to prevent damage and injury to passengers. Investigation of the energy absorption behaviour of composite materials presents a unique combination of weight loss and vehicle safety improvement or provides at least the same safety in accidents compared to metal structures [2]. In other words, application of composite materials in crash boxes increases specific energy absorption, due to their lower density than metals [3].

In recent years, many studies were conducted about replacing metal thin walls with composite ones. In this regard, Jahani et al. [4] studied crashworthiness of composite and aluminium thin-walled boxes numerically. Teng and $\mathrm{Hu}$ [5] and Song et al. [6] 
investigated the improvement of hollow cylindrical thin-walled structure behaviours by strengthening them with fibre reinforced composites. Advantages of replacing steel hollow cylindrical thin-walled structures with composites one is investigated under bending by Haedir et al. [7, 8], under bending and compression by Doi et al. and Baroutaji et al. [9, 10], under tension by Jiao and Zhao [11], Zhao et al. [12], and Xiao et al [13], under transverse loading and shear force by Zhao et al. [14]. The finite element modeling was also carried out by Fernando et al. [15]. Reuter and Troster [16] investigated crashworthiness and numerical simulation of aluminum and carbon fibre reinforced polymer (CFRP) hybrid tubes under axial impact. They achieved that the specific energy absorption is higher compared to a pure aluminum structure. Wu et al. [17] investigated quasi-static axial crush response and energy absorption of layered composite structure formed from novel crochet-sintered mesh tube and thin-walled tube. They concluded that the layered composite tubes showed great potential for application as energy absorbers.

Various parameters affect the crashworthiness behaviour of crash boxes. These parameters can be divided into the following groups: type of material, geometrical properties (diameter and thickness), section shape, triggering mechanisms, filling with foam or honeycomb, using sandwich panels. Crash boxes have been made in different geometries and some researchers studied the effects of geometry and shape on the crash boxes performance. Thin-walled crash boxes with different cross-sections such as cylindrical [18-22], square [23-26], cylindrical corrugated composite thin-walled structures [27], hexagonal and octagonal composite thin-walled structures [28, 29], cone composite thin-walled structures with elliptical section [20] and composite systems with geometry of cone-cylinder-cone [30] were designed and tested. Elgalai et al. [31] conducted extensive experimental work in cylindrical glass/epoxy thin-walled structures under quasi-static compression to study the effects of length on collapse modes behaviour and energy absorption capability of samples. Their results show that the collapse behaviour and energy absorption capability is sensitive to the length change. Mamalis et al. [32] studied energy absorption behaviour and collapse modes of cylindrical carbon fibre reinforced polymer (CFRP) thin-walled structures under axial quasi-static compression load. They examined the effects of geometric properties such as axial length, aspect ratio and wall thickness on the compression response and collapse modes of experimental samples. Palanivelu et al. [33] presented nine different geometrical shapes of composite tubes.

It was found that the crushing characteristics and the corresponding energy absorption of the special geometrical shapes are better than the standard geometrical shapes such as square and hexagonal cross sections. Furthermore, the tulip triggering caused lowering peak crush load. Zhang et al. [34] investigated the impacts of geometrical parameters on the specific energy absorption (SEA) of composite tubes, metal tubes, foam-filled tubes and hybrid tubes. Their results showed that changing upper end diameter of tubes had great impacts on their energy absorption capacity. Recently, some researchers $[35,36]$ investigated crashworthiness of multi-cell tubes because of their excellent influence on energy absorption capacity. Vinayagar and Kumar [37] studied crashworthiness of double section bi-tubular thin-walled structures. Bi-tubular structures had more energy absorption capability than the single cylinder.

Many researchers studied metal energy absorbers filled with metallic foams and their applications in order to increase the capability of energy absorption of some special structures. In the automotive industries, application of lightweight materials in vehicle components seems appropriate due to reduction of the mass of the vehicles. That is why composite materials with a higher strength to weight ratio compared to metals, are rapidly 
replacing some metal parts in automobiles and vehicles. In recent years, the energy absorption behaviour and the impact response of foam-filled composite structures to absorb impact energy attracted some researcher attentions in the world. In 2016, Hossein et al. [38] studied axial collapse behaviour of hollow and honeycomb filled cylindrical composite thin-walled structures under the velocity of $0.05,0.5,5$ and $50 \mathrm{~mm} / \mathrm{s}$. Their results showed that the mean load and absorbed energy of honeycomb filled samples were higher than hollow ones. Mohammadiha et al. [39] studied the crashworthiness of the functionally graded honeycomb filled box structures. They proved its superiority with respect to the uniform honeycomb filled box structures. Gan et al. [40] investigated the collapse behaviour and energy absorption of cylindrical, hexagonal and square hollow thin-walled structures of CFRP composite and aluminium. They also investigated Aluminium and polyurethane foam-filled structures under axial quasi-static compressive load and indicated that cylindrical composite structure filled with polyurethane foam had higher energy absorption capability than, hexagonal and square sections. Furthermore, specific energy absorption of composite structures filled with polyurethane foam was $30 \%$ higher than aluminium structures filled with aluminium foam which were used in their work. Wang et al. [41] investigated energy absorption capability and the collapse behaviour of cylindrical glass fibre reinforced polymer (GFRP) composite structures under axial loading. They studied the effects of thickness, diameter, foam density and ply orientations on the maximum load, load efficiency and energy absorption. They showed that increasing the thickness and foam density could increase the maximum force in addition to increasing energy absorption capacity. Li et al. [42] did a comparative analysis of crashworthiness of empty and foam-filled thin-walled tubes. They found that foamfilled circular tube structures are recommended as crashworthy structures due to their high crush force efficiency and energy-absorbing efficiency.

In the present study, the effects of diameter and thickness of a crash box, different types of edge triggering and polymeric foam-filling on the crashworthiness of a crash box simultaneously are investigated. To this end, the simulation of a crash box with special condition which was experimentally tested in Ref. [43] is done to achieve an accurate way in simulating (section 3). Then, for parametric study, another model of crash box is simulated (section 4 and go on) and a new dimensionless parameter $(\beta)$ is defined to evaluate better performance with considering all important parameters. rs. This study is preferable to others for the simultaneous investigation of the effect of some factors (above mentioned) on the crash box behaviour and formulation of a dimensionless parameter for evaluating its performance.

\section{IMPORTANT PARAMETERS FOR AN OPTIMISED CRASH BOX}

There are three parameters usually used for evaluating the crashworthiness performance of a crash box. This parameter shows the total energy absorbed by the structure during the impact process equals to the area under the force-displacement curve as in Eq. (1).

$$
\mathrm{TEA}=\int_{0}^{\mathrm{d}} \mathrm{Fdx}
$$

One of the most important parameters to evaluate the performance of crash boxes is their specific energy absorption which is defined as absorbed energy per unit mass as in Eq. (2). 


$$
\mathrm{SEA}=\frac{1}{\mathrm{~m}_{\mathrm{c}}} \int_{0}^{\mathrm{d}} \mathrm{Fdx}
$$

that $\mathrm{m}_{\mathrm{c}}$ is total mass of the structure. Force efficiency in Eq. (3) is defined as mean force to the maximum force shows the ability of crash boxes from load viewpoint.

$$
\eta=\frac{F_{\text {mean }}}{F_{\max }}
$$

High value of $\eta$ shows the difference between the maximum and mean forces decrease and consequently the performance of crash box increases.

\section{FINITE ELEMENT MODELING VALIDATION}

\section{Geometry, Materials and Simulation}

In this study, a crash box is modelled in the commercial finite element solver Abaqus/Explicit. The geometrical and material properties of sample are extracted from research by Chiu et al. [43]. Figure 1 shows a schematic of a composite sample with tulip triggering. The model is meshed with 5522 four-node shell elements (S4R). Table 1 presents mechanical properties of T700/M21 composite. $\rho$ is density, $E_{11}$ and $E_{22}$ are moduli of elasticity along fibre direction and perpendicular to the fibre direction, $G_{12}$ and $G_{23}$ are shear moduli and $v$ is Poisson's ratio. $X_{\mathrm{t}}$ and $X_{\mathrm{c}}$ are tensile and compression strengths along fibres, $Y_{t}$ and $Y_{c}$ are tensile and compression strengths perpendicular to the fibres. $G_{f t}^{c}, G_{f c}^{c}, G_{m t}^{c}$ and $G_{m c}^{c}$ are fracture energy related to fibre tension, fibres compression, matrix tension and matrix compression, respectively.

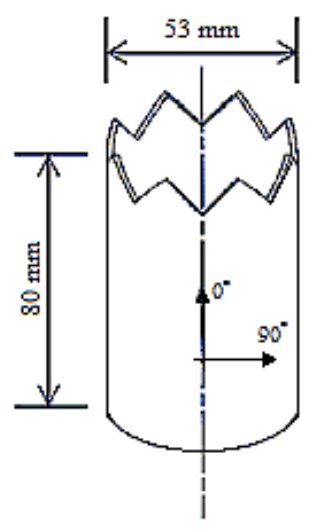

Figure 1. Schematic of a composite sample used by Chiu et al. [43].

According to Figure 2, the sample is located between two rigid plates. The bottom plate is tied to the sample and completely fixed and the other one impacts the sample with velocity of $0.5 \mathrm{~mm} / \mathrm{min}$ [40] in the axial direction. It is tried to implement the real boundary conditions in the simulation as it occurs in the experimental fixtures. Stacking sequence of the composite layup is [0/90/0/90]s. Wall thickness is $1.2 \mathrm{~mm}$. A general contact is defined between all surfaces. Since during the collapse of the structure, 
elements are in contact with themselves, self-contact is used. To speed up the running process, a mass-scaling factor has been used.

Table 1. Mechanical properties of T700/M21 composite [43].

\begin{tabular}{lc}
\hline Material properties & Value \\
\hline$\rho\left(\mathrm{kg} / \mathrm{m}^{3}\right)$ & 1590 \\
$E_{11}(\mathrm{GPa})$ & 142 \\
$E_{22}(\mathrm{GPa})$ & 8.40 \\
$G_{12}(\mathrm{GPa})$ & 4.80 \\
$G_{23}(\mathrm{GPa})$ & 2.90 \\
$v_{12}$ & 0.32 \\
$X_{t}(\mathrm{MPa})$ & 2282 \\
$X_{c}(\mathrm{MPa})$ & 1465 \\
$Y_{t}(\mathrm{MPa})$ & 65 \\
$Y_{c}(\mathrm{MPa})$ & 290 \\
$\mathrm{G}_{\mathrm{ft}}^{\mathrm{c}}\left(\mathrm{kJ} / \mathrm{m}^{2}\right)$ & 108 \\
$\mathrm{G}_{\mathrm{fc}}^{\mathrm{c}}\left(\mathrm{kJ} / \mathrm{m}^{2}\right)$ & 58.40 \\
$\mathrm{G}_{\mathrm{mt}}^{\mathrm{c}}\left(\mathrm{kJ} / \mathrm{m}^{2}\right)$ & 0.33 \\
$\mathrm{G}_{\mathrm{mc}}^{\mathrm{c}}\left(\mathrm{kJ} / \mathrm{m}^{2}\right)$ & 1.10 \\
\hline
\end{tabular}

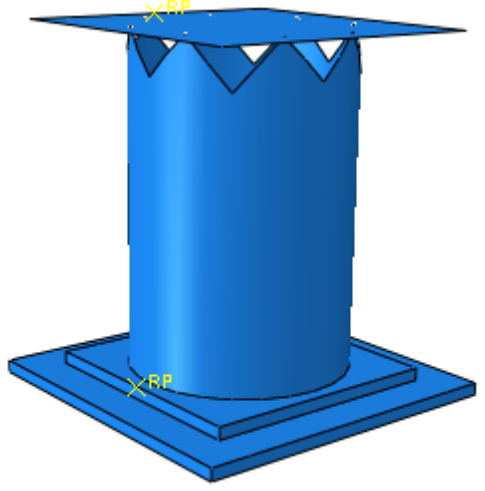

Figure 2. A three-dimensional model.

\section{Hashin Damage Criterion}

There are several failure criteria for damage analysis of composite materials. Hashin damage criterion gives relatively good predictions as well as failure modes. It is available in software and it can be used for prediction of damage initiation and linked with material degradation rules to provide the capability of damage evolution base on the fracture energies of different failure modes [44]. Modified Hashin damage criterion is represented as follows:

$$
\begin{array}{ll}
\mathrm{F}_{\mathrm{f}}^{\mathrm{t}}=\left(\frac{\sigma_{11}}{\mathrm{X}_{\mathrm{t}}}\right)^{2}+\alpha\left(\frac{\tau_{12}}{\mathrm{~S}_{1}}\right)^{2} & \sigma_{11} \geq 0 \\
\mathrm{~F}_{\mathrm{f}}^{\mathrm{c}}=\left(\frac{\sigma_{11}}{\mathrm{X}_{\mathrm{c}}}\right)^{2} & \sigma_{11} \leq 0
\end{array}
$$




$$
\begin{array}{ll}
\mathrm{F}_{\mathrm{m}}^{\mathrm{t}}=\left(\frac{\sigma_{22}}{\mathrm{Y}_{\mathrm{t}}}\right)^{2}+\left(\frac{\tau_{12}}{\mathrm{~S}_{1}}\right)^{2} & \sigma_{22} \geq 0 \\
\mathrm{~F}_{\mathrm{m}}^{\mathrm{c}}=\left(\frac{\sigma_{22}}{2 \mathrm{~S}_{\mathrm{t}}}\right)^{2}+\left[\left(\frac{\mathrm{Y}_{\mathrm{c}}}{2 \mathrm{~S}_{\mathrm{t}}}\right)^{2}-1\right] \frac{\sigma_{22}}{\mathrm{Y}_{\mathrm{c}}}+\left(\frac{\tau_{12}}{\mathrm{~S}_{1}}\right)^{2} & \sigma_{22} \leq 0
\end{array}
$$

where $\sigma_{11}, \sigma_{22}$ and $\tau_{12}$, are the components of the stress tensor. $S_{l}$ is in-plane shear strength and $S_{t}$ is transverse shear strength. $F_{f}^{t}, F_{f}^{c}, F_{m}^{t}$ and $F_{m}^{c}$ are calculated values after replacing the stresses and strengths in relations that if any of these values equal to or greater than one, failure happens. Before damage initiation, material behaviour is linear elastic, and after that the stress-strain relation is:

$$
\sigma=\mathrm{C}_{\mathrm{d}} \varepsilon
$$

$\mathrm{Cd}$ is the matrix of damaged stiffness and is defined in Eq. (9).

$$
\mathrm{C}_{\mathrm{d}}=\frac{1}{\Delta}\left[\begin{array}{ccc}
\left(1-\mathrm{d}_{\mathrm{f}}\right) \mathrm{E}_{1} & \left(1-\mathrm{d}_{\mathrm{f}}\right)\left(1-\mathrm{d}_{\mathrm{m}}\right) v_{21} \mathrm{E}_{1} & 0 \\
\left(1-\mathrm{d}_{\mathrm{f}}\right)\left(1-\mathrm{d}_{\mathrm{m}}\right) v_{12} \mathrm{E}_{2} & \left(1-\mathrm{d}_{\mathrm{m}}\right) \mathrm{E}_{2} & 0 \\
0 & 0 & \left(1-\mathrm{d}_{\mathrm{s}}\right) \mathrm{GD}
\end{array}\right]
$$

that $D$ is defined according to Eq. (10).

$$
\Delta=1-\left(1-\mathrm{d}_{\mathrm{f}}\right)\left(1-\mathrm{d}_{\mathrm{m}}\right) v_{12} v_{21}
$$

where $d_{f}, d_{m}$ and $d_{s}$ are damage variables and indicate the current status of fibre damage, matrix damage and shear damage, respectively. $d_{f}, d_{m}$, and $d_{s}$ are derived from four damage variables, $d_{f}^{t}, d_{f}^{c}, d_{m}^{t}$ and $d_{m}^{c}$ based on four failure modes as follows:

$$
\begin{aligned}
& d_{f}= \begin{cases}d_{f}^{t} & \text { if } \hat{\sigma}_{11} \geq 0 \\
d_{f}^{c} & \text { if } \hat{\sigma}_{11}<0\end{cases} \\
& d_{m}= \begin{cases}d_{m}^{t} & \text { if } \hat{\sigma}_{22} \geq 0 \\
d_{m}^{c} & \text { if } \hat{\sigma}_{22}<0\end{cases} \\
& d_{s}=1-\left(1-d_{f}^{t}\right)\left(1-d_{f}^{c}\right)\left(1-d_{m}^{t}\right)\left(1-d_{m}^{c}\right)
\end{aligned}
$$

that $\hat{\sigma}_{11}$ and $\hat{\sigma}_{22}$ are effective stress tensor components. For more information, see reference [45]. Abaqus also uses a characteristic length, $l_{c}$ to reduce dependency to the element size. Modified Hashin damage criterion is neglecting the effect of fibre pull out from the matrix during the failure.

The positive gradient of the stress-displacement curve is related to the linear elastic behaviour of the material before the damage initiation and the negative gradient is related to the behaviour of the material after the damage initiation. Damage variable can be presented versus displacement for linear softening as follows: 


$$
\mathrm{d}=\frac{\delta_{\mathrm{eq}}^{\mathrm{f}}\left(\delta_{\mathrm{eq}}-\delta_{\text {eq }}^{0}\right)}{\delta_{\text {eq }}\left(\delta_{\text {eq }}^{\mathrm{f}}-\delta_{\text {eq }}^{0}\right)}
$$

$\delta_{\text {eq }}^{0}$ and $\delta_{\text {eq }}^{\mathrm{f}}$ are the initial equivalent displacement and equivalent displacement when damage occurs entirely in every mode. The value of $\delta_{e q}^{f}$ in each mode depends on the fracture energy, $G_{c}$. The value of $G_{c}$ equals to the area under the equivalent stressdisplacement curve. Fracture energy is different for each failure mode. Thereafter, $G_{f t}^{c}$, $G_{f c}^{c}, G_{m t}^{c}$ and $G_{m c}^{c}$ are the fracture energies related to the fibre tension, fibres compression, matrix tension and matrix compression, respectively.

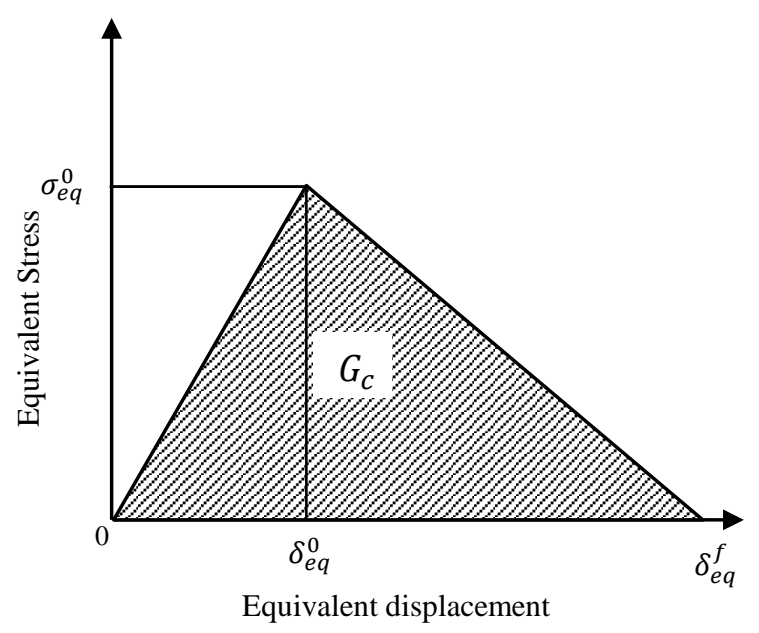

Figure 3. Equivalent stress-displacement for progressive damage in Abaqus/Explicit [45].

\section{Validation of Numerical Simulation}

Figure 4 shows force-displacement curves obtained from experimental results [43] and numerical simulations of present study. Crashworthiness parameters of this crash box are compared in Table 2. Error percentage for absorbed and specific energy is $10 \%$ and for the maximum force is about $8 \%$. So, $2 \mathrm{D}$-elements in addition to reducing time cost could provide acceptable results. Figure 5 also illustrate experimental collapse behaviour [43] and deformation of experimented and simulated samples. The simulation results are acceptable and are in good agreement with experimental results as shown by Figure 4 and 5 , and Table 2.

Table 2. Comparison of crashworthiness parameters obtained from experiment and FE.

\begin{tabular}{lccc}
\hline & Experiment $[43]$ & FE-present study & Error $(\%)$ \\
\hline$F_{\text {mean }}(\mathrm{kN})$ & 12.74 & 11.70 & 8.10 \\
$F_{\text {max }}(\mathrm{kN})$ & 17.50 & 18.90 & 8 \\
$\eta$ & 0.72 & 0.61 & 15.20 \\
$S E A(\mathrm{~J} / \mathrm{g})$ & 19.05 & 17.11 & 10.10 \\
\hline
\end{tabular}




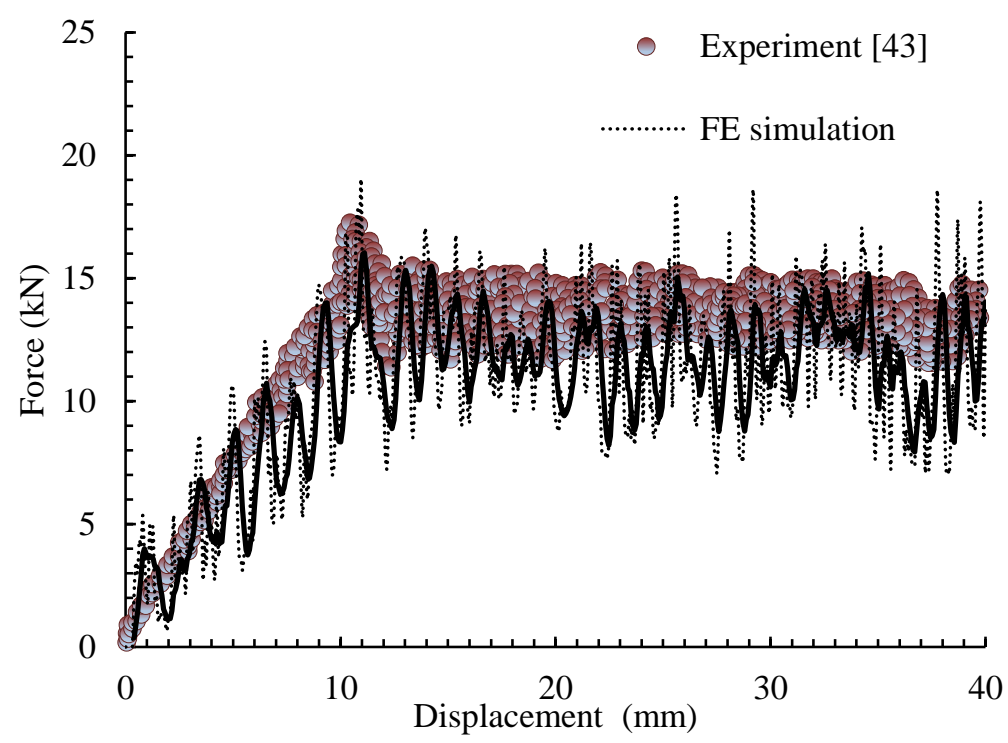

Figure 4. Comparison of experimental and FE load-displacement curves under axial crush loading.

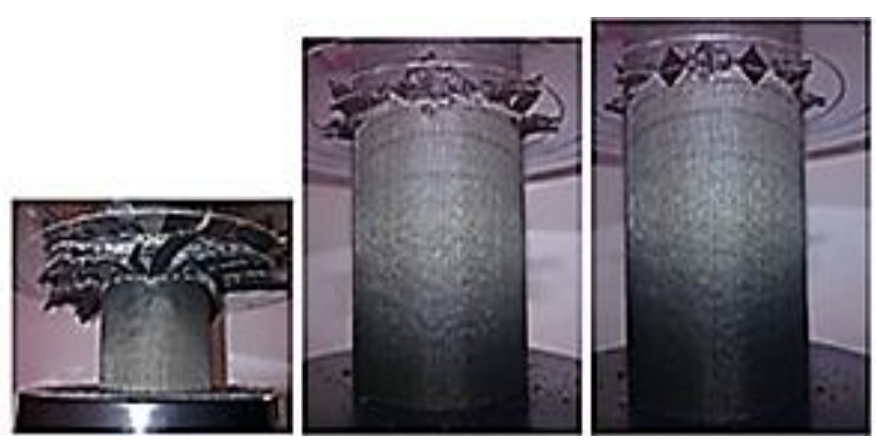

(a)

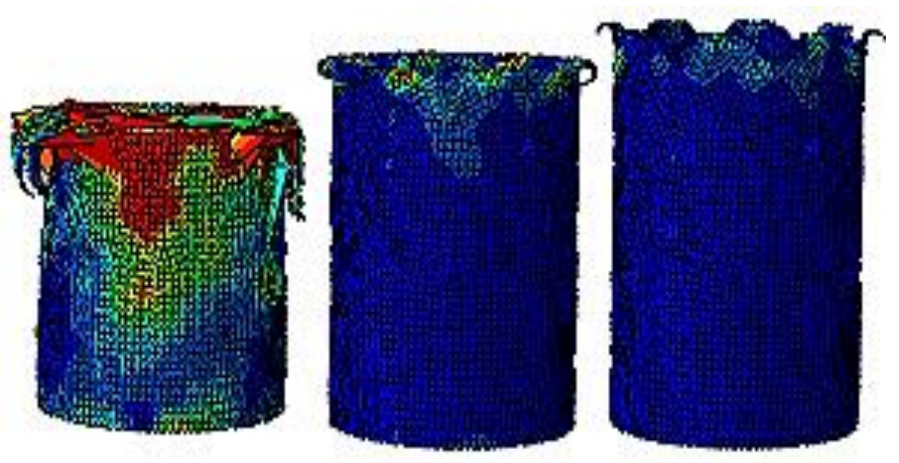

(b)

Figure 5. Collapse behaviour of composite crash box: (a) recorded in lab [43], and (b) modelled as shell (with conventional-shell elements in this paper).

\section{CRASH BOX FINITE ELEMENT MODELING WITH NEW CONDITION}

The aim of this study is to evaluate the effects of different variables such as geometry, triggering and foam-filling on the crashworthiness of a crash box. To reach this goal, a 
unique condition should be applied for each simulation. Cylindrical crash boxes are more appropriate with desired results [46, 47]. ،the length of $200 \mathrm{~mm}$ and impact velocity of 6 $\mathrm{m} / \mathrm{s}$ are considered the same in all simulations [48-50]. Therefore, a cylindrical tube with length of $200 \mathrm{~mm}$, stacking sequence of [0/90/0/90 $]_{\mathrm{s}}$ and material of T700/M21 composite is simulated. In this simulation the bottom end of the structure is fixed and impact took place in another end. Impactor plate and bottom component are defined as rigid and the crash box is defined as a shell due to its small wall thickness. In general, layers can be defined as conventional and continuum shell. Here conventional shell is used because of less time cost with desired results. A general contact is defined between all surfaces. Since during collapse of the structure, elements are in contact with themselves, self-contact is used for the crash box.

\section{EFFECTS OF VARIOUS PARAMETERS ON THE CRASHWORTHINESS OF A COMPOSITE CRASH BOX}

\section{Effects of Geometry}

To study the effect of geometry including diameter and thickness on the crash behaviour of a composite crash box, two groups of simulations are considered, a) a $1.5 \mathrm{~mm}$-thickness crash box with eighteen different diameters; b) a $100 \mathrm{~mm}$-diameter crash box with seven different thicknesses. Diameter of crash boxes was changed from $70 \mathrm{~mm}$ to $240 \mathrm{~mm}$. Similar to diameter, effects of thickness on the performance of composite crash box under the expressed condition are investigated in constant diameter of $100 \mathrm{~mm}$. Simulation is repeated seven times for different values of thicknesses $(4,3.5,3,2.5,2,1.5$ and $1 \mathrm{~mm})$.

\section{Effects of Triggering}

Triggering is known as a structural defect in crash boxes that is designed to reduce the maximum load. In this study, the effects of three different types of edge triggers, i.e., chamfer, fillet and tulip (the same trigger in Chiu et al. [43]) in upper edge were studied. Figure 6 shows the three types of simulated triggers. All three triggers geometry have the same depth from the edge of crash box.

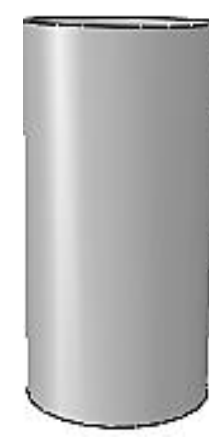

(a)

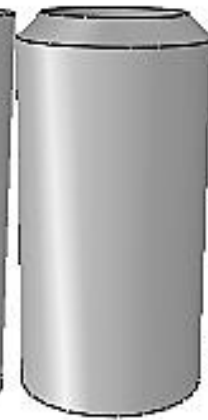

(b)

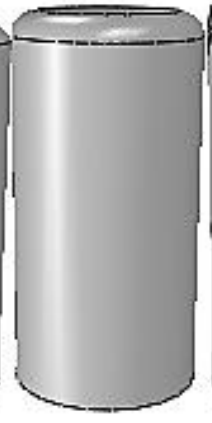

(c)

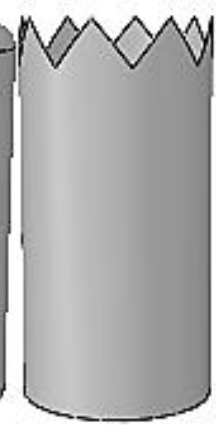

(d)

Figure 6. Types of simulated triggers: (a) without trigger, (b) chamfer, (c) fillet and; (d) tulip. 
Triggering mechanism allows local buckling and depending on its type provides the possibility of progressive deformation. The place of trigger in the structure affects the collapse behaviour. The size and shape of the inner edges are effective on the maximum load. Therefore, the geometry of the edges of the structure should be changed to reduce the maximum load.

\section{Effects of Foam-Filling}

Filling the thin-walled structures with foam generally has positive effects on their energy absorption. In this regard, the simulated crash box is filled with a polymeric foam in this section. In order to evaluate the foam-filling on the performance of a composite crash box, simulation is performed on a crash box with $1.5 \mathrm{~mm}$ thickness, $100 \mathrm{~mm}$ diameter and the tulip triggering. To do this, expanded polypropylene (EPP) foam is used. EPP is an elastic-plastic polymeric foam with closed cell structure, it is very flexible, light, and resistant to shock and impact, and has many applications. This foam has unique features, including excellent energy absorption, high impact resistance, and high strength to weight ratio. It can be made in different density from 15 to $200 \mathrm{~kg} / \mathrm{m}^{3}$. Figure 7 shows the engineering stress-strain behaviour of EPP foam with a density of $55 \mathrm{~kg} / \mathrm{m}^{3}$. EPP is modelled as a linear elastic material with strain hardening.

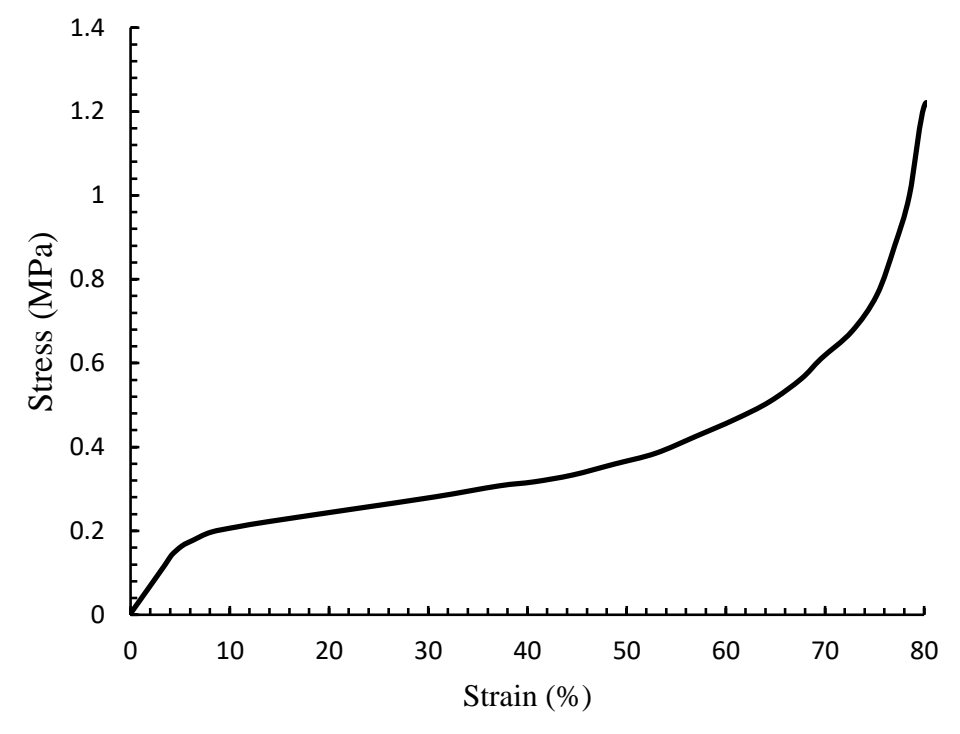

Figure 7. Stress-strain curve of elastic-plastic EPP foam [51].

To define the foam behaviour, it is necessary to define true stress and volumetric logarithmic plastic strain [51].

$$
\begin{aligned}
& \sigma_{\text {true }}=\sigma_{\text {eng }}\left(1+\varepsilon_{\text {eng }}\right) \\
& \varepsilon_{\text {true }}=\ln \left(1+\varepsilon_{\text {eng }}\right) \\
& \varepsilon_{\mathrm{pl}}=\varepsilon_{\text {true }}-\frac{\sigma_{\mathrm{y}}}{E} \\
& \varepsilon_{\mathrm{v}}=\ln \left(1+\varepsilon_{\mathrm{pl}}\right)
\end{aligned}
$$


In these equations, $\sigma_{\text {true }}$ and $\sigma_{\text {eng }}$ are true and engineering stresses and $\varepsilon_{\text {true }}, \varepsilon_{\text {eng }}$, $\varepsilon_{p l}$ and $\varepsilon_{v}$ are true strain, engineering strain, plastic strain and volumetric logarithmic plastic strain, respectively. Volumetric strain hardening was modelled by activating hardening option in the software. Plastic behaviour of this foam was defined by data extracted from Figure 7 and using Eq. (15) to (18). Table 3 presents the mechanical properties of EPP foam [51].

Table 3. Mechanical properties of EPP foam [51].

\begin{tabular}{llll}
\hline Foam & $\rho\left(\mathrm{kg} / \mathrm{m}^{3}\right)$ & $E(\mathrm{MPa})$ & $v$ \\
\hline EPP & 52 & 3.87 & 0.30 \\
\hline
\end{tabular}

\section{DEFINITION OF PERFORMANCE PARAMETER}

An ideal crash box performs the high specific energy absorption, low maximum force, and minimum difference between the maximum and mean loads. One of the aims of this study is to investigate the simultaneous effects of different variables on the specific energy, the maximum load and mean load. Having a positive effect of all parameters is not always possible. To this end, a performance parameter is defined to include $S E A, F_{\text {mean }}$ and $F_{\max }$. The result of multiplication of $\eta$ and $S E A$ is placed in the form of a fraction and $F_{\max }$ is placed in the denominator. In this way, the positive effect of each parameter (increasing $\eta$ and $S E A$ and decreasing $F_{\max }$ ) leads to an increase in the value of this function. Performance parameter is defined as follows:

$$
\beta=\frac{\eta \times \mathrm{SEA} \times \mathrm{M}}{\mathrm{F}_{\max } \times \mathrm{L}}=\frac{\mathrm{F}_{\text {mean }} \times \mathrm{E} \times \mathrm{M}}{\mathrm{F}_{\max }^{2} \times \mathrm{L} \times \mathrm{m}}
$$

To obtain a dimensionless parameter, a constant value with the unit of $\mathrm{kg} / \mathrm{m}$ should be multiplied. So, this function that is shown with $\beta$, is multiplied by the mass of the impactor and divided to the length of the crash box that respectively are $300 \mathrm{~kg}$ and $0.2 \mathrm{~m}$ in this study. Finally, the performance parameter in Eq. (19) is simplified as follows:

$$
\beta=1500 \times \frac{F_{\text {mean }} \times \text { SEA }}{F_{\text {max }}^{2}}
$$

In Eq. (20), specific energy absorption and the maximum load are in $\mathrm{J} / \mathrm{g}$ and $\mathrm{kN}$, respectively. A higher value of performance function $(\beta)$ leads to better performance of the crash box.

\section{RESULTS AND DISCUSSION}

Table 4 shows the results of the most important parameters for crash boxes with different simulated diameters and Figure 8 indicates ascending behaviour of the maximum load and absorbed energy of structures by increasing the diameter. By examining the effects of diameter in this study and considering the value of performance function $(\beta)$ in Figure 9 , the crash box with diameter of $100 \mathrm{~mm}$ has a better performance compared to other 
diameters. However, this superiority has only been in comparison to other diameters. It also has the highest specific energy absorption.

Table 4. Effects of diameter on the crashworthiness parameters.

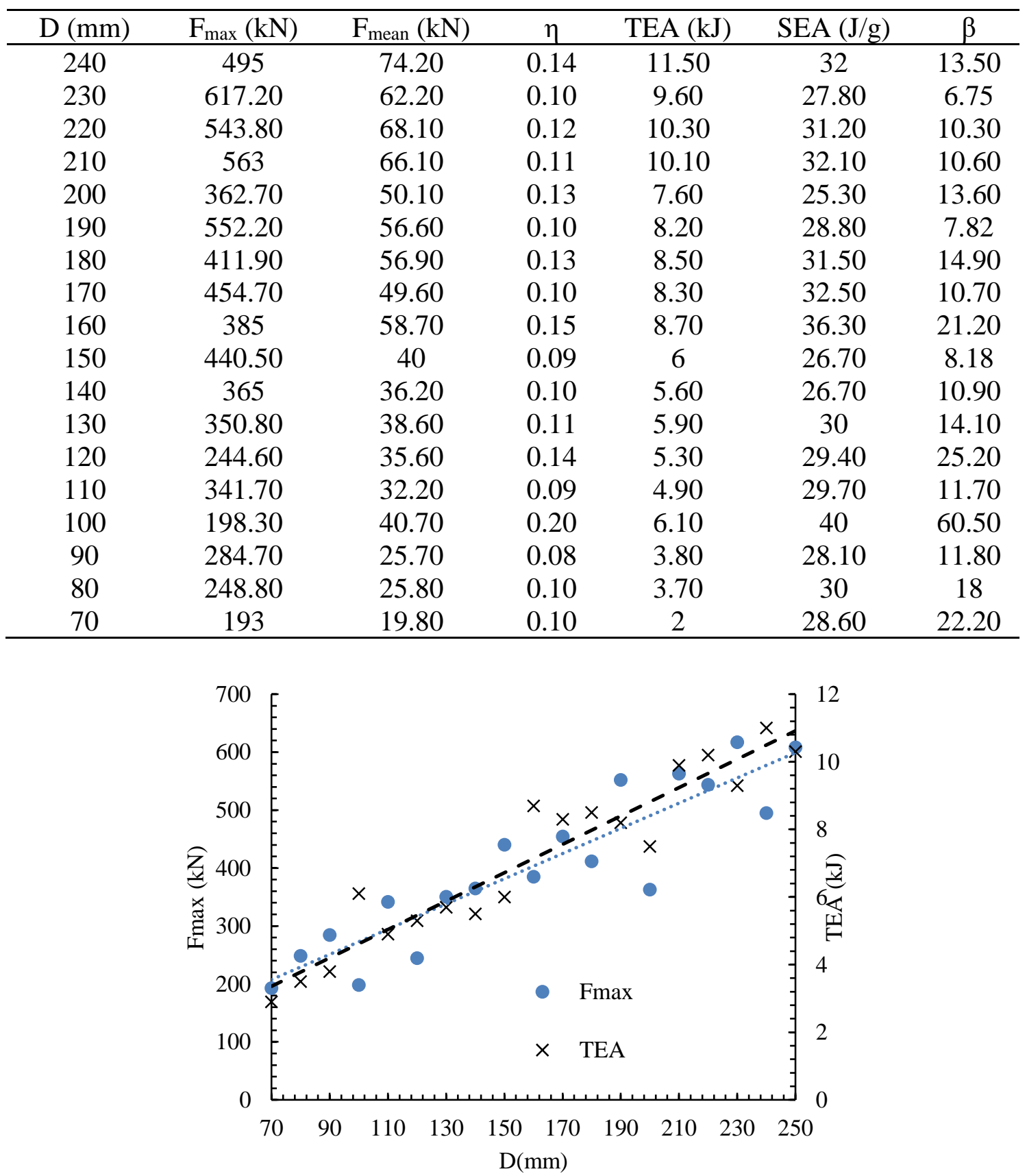

Figure 8. Effect of diameter on the maximum load and the absorbed energy. 


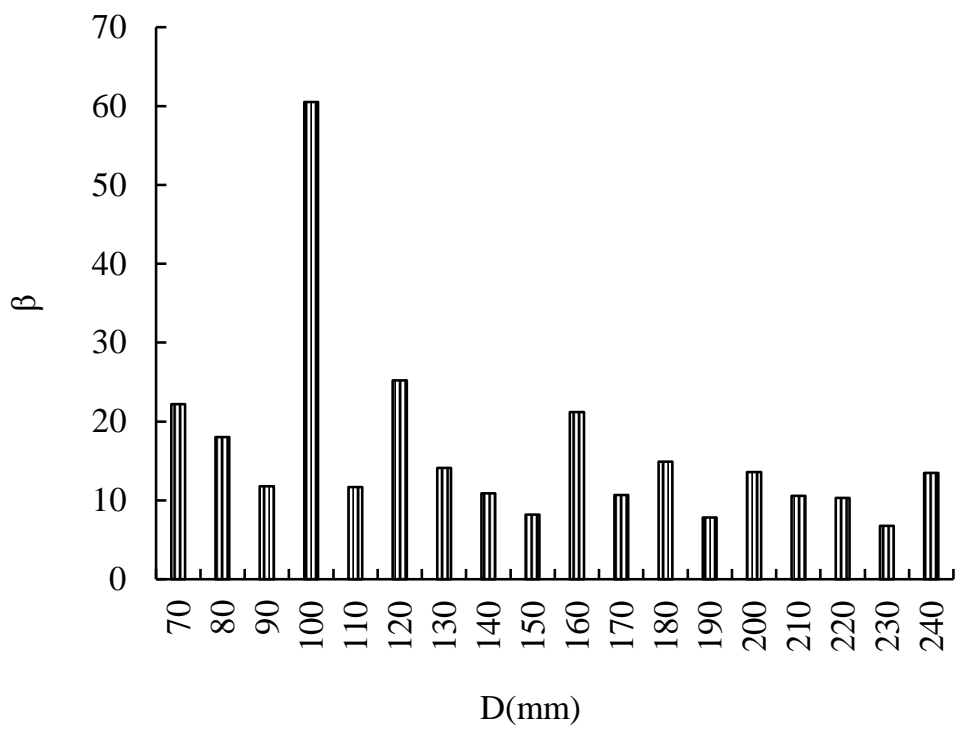

Figure 9. Effect of diameter on the performance parameter $(\beta)$.

Ignoring the simulation errors, it can be seen that by increasing the diameter, absorbed energy and the maximum load increase. Similar results were reported by Mamalis et al. [52] as well. Table 5 shows the results of the crashworthiness parameters of crash boxes with different thicknesses. Figure 10 shows the ascending behaviour of the maximum load and absorbed the energy of structures by increasing the thickness. By considering the value of performance function $(\beta)$ in Figure 11, the crash box with a thickness of $1.5 \mathrm{~mm}$ is more suitable in a crash scenario. However, this superiority is only compared to other simulated thickness sizes and is not the best. In general, and ignoring the simulation errors, it can be seen that by increasing the thickness, absorbed energy and the maximum load increased, and the behaviour of the specific energy absorption is not predictable. Similar results were reported by some researchers [52-54].

Table 5. Effects of thickness on the crashworthiness parameters of a composite crash box.

\begin{tabular}{lcccccc}
\hline $\mathrm{t}(\mathrm{mm})$ & $\mathrm{F}_{\max }(\mathrm{kN})$ & $\mathrm{F}_{\text {mean }}(\mathrm{kN})$ & $\eta$ & $\begin{array}{c}\text { TEA } \\
(\mathrm{kJ})\end{array}$ & SEA $(\mathrm{J} / \mathrm{g})$ & $\beta$ \\
\hline 1 & 231.20 & 25.10 & 0.10 & 3.70 & 37 & 24 \\
1.50 & 198.30 & 40.70 & 0.20 & 6.10 & 40 & 60.50 \\
2 & 297 & 33.20 & 0.11 & 5 & 25 & 13.80 \\
2.50 & 392.50 & 45.10 & 0.11 & 6.70 & 26.80 & 11.20 \\
3 & 566 & 47.70 & 0.08 & 7.20 & 24 & 5 \\
3.50 & 500.20 & 71 & 0.14 & 10.80 & 30.90 & 12.90 \\
4 & 773.10 & 84.80 & 0.10 & 13 & 32.50 & 6.30 \\
\hline
\end{tabular}

Figure 12 indicates the load-displacement curve of various crash boxes with and without triggers. Triggering reduces the maximum load and increases the area under the curve. Investigation of Figure 13 shows a positive effect of triggering in the design and structure of crash boxes with the changes in values of the maximum load, specific energy absorption, and the load efficiency. 


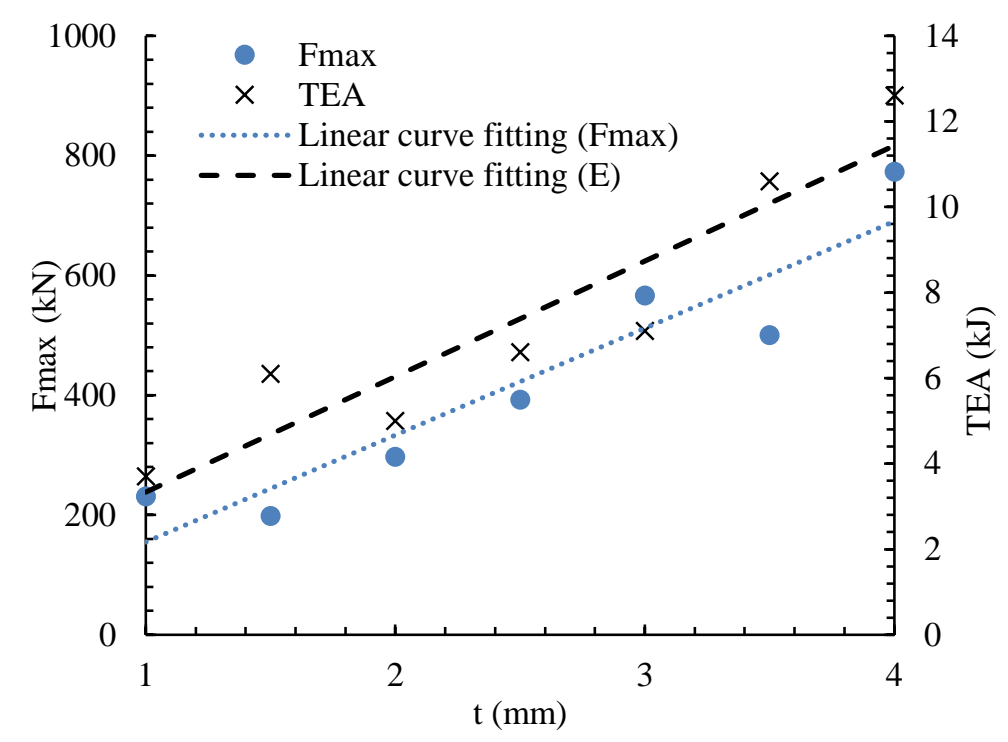

Figure 10. Effect of thickness on the maximum load and the absorbed energy.

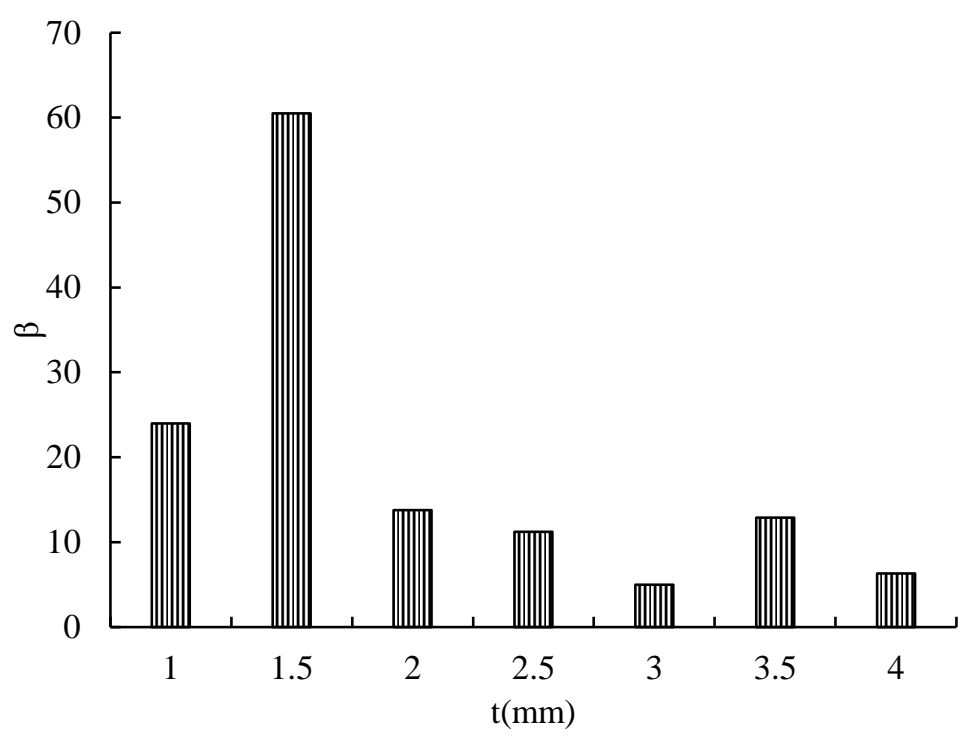

Figure 11. Effect of thickness on the performance parameter $(\beta)$.

Table 6 summarises the values of the maximum force, mean force, load efficiency, specific energy absorption and performance function for simulated crash boxes without triggering and with three different trigger mechanisms. The results show that trigger mechanisms reduced the maximum load and had a good influence on the load efficiency and energy absorption similar results were reported in previous works [33, 55]. Also, tulip trigger is more effective according to the performance parameter $\beta$. 


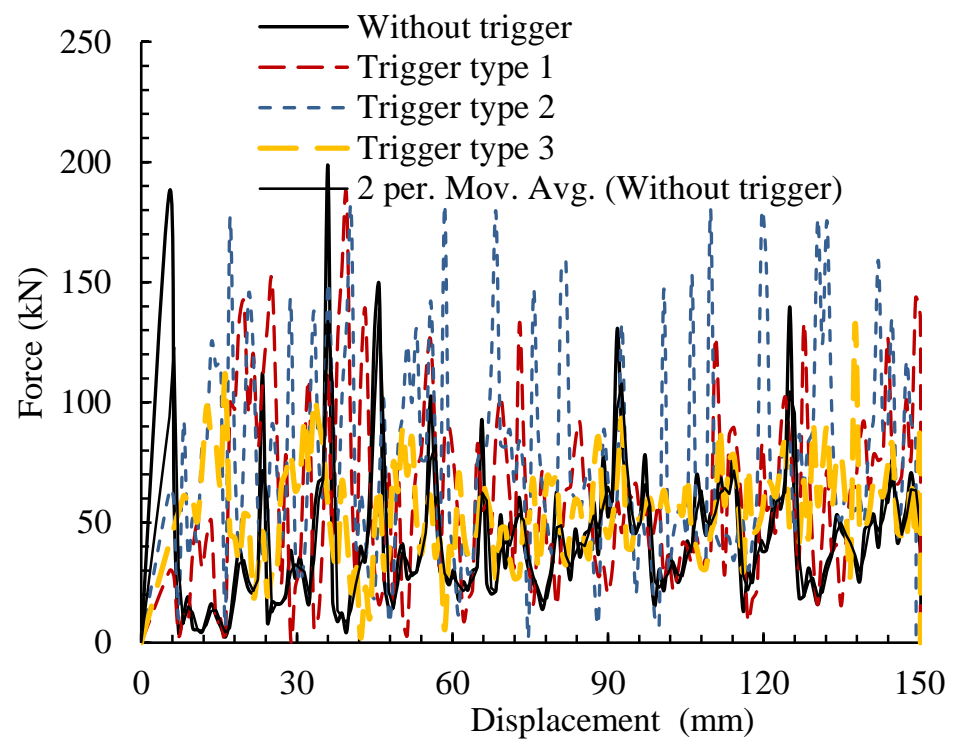

Figure 12. Comparison of force-displacement curves with three different types of trigger mechanisms.

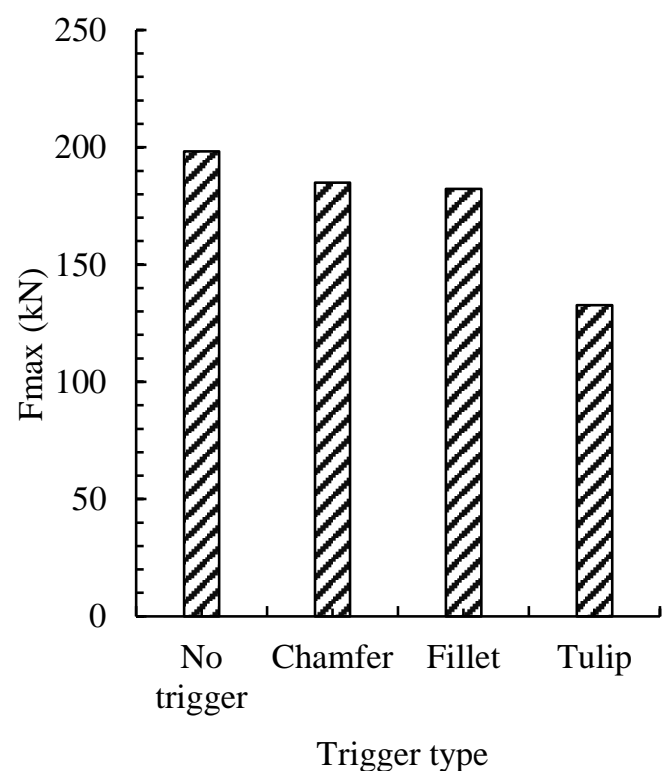

(a)

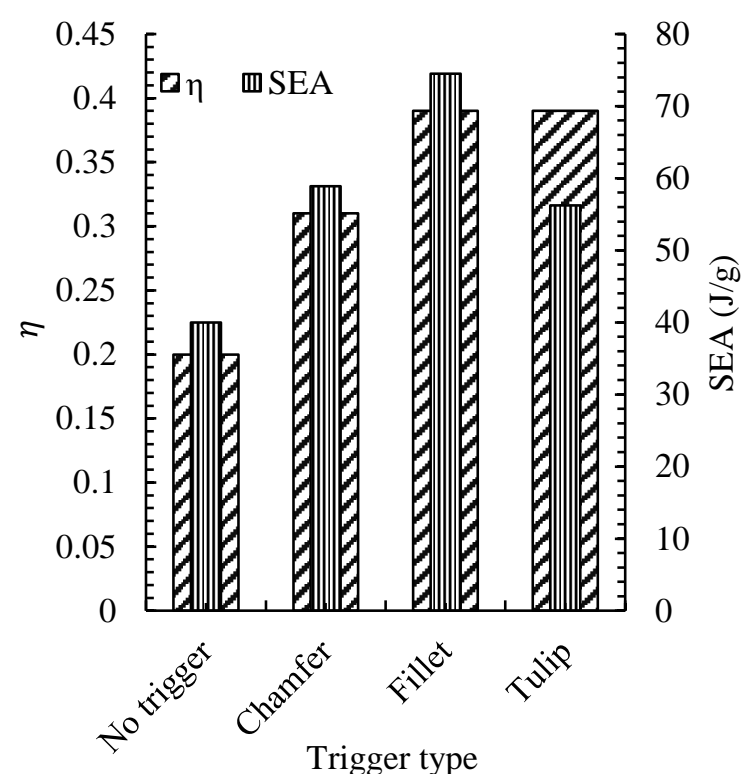

(b)

Figure 13. Effect of trigger on: (a) the maximum force, (b) specific energy absorption and force efficiency for a composite crash box.

Table 6. Crashworthiness parameters of simulated crash boxes with/without a trigger.

\begin{tabular}{lcccc}
\hline Trigger type & No trigger & Chamfer & Fillet & Tulip \\
\hline$F_{\text {max }}(\mathrm{kN})$ & 198.30 & 185 & 182.30 & 132.70 \\
$F_{\text {mean }}(\mathrm{kN})$ & 40.70 & 58.90 & 72.50 & 52.70 \\
$S E A(\mathrm{~J} / \mathrm{g})$ & 40 & 58.90 & 74.50 & 56.20 \\
$\eta$ & 0.20 & 0.31 & 0.39 & 0.39 \\
$\beta$ & 60.50 & 148 & 127 & 247.70 \\
\hline
\end{tabular}


Figure 14 shows the load-displacement curves empty and foam-filled crash boxes with tulip triggering under the same conditions. Table 7 presents the important and effective parameter results for empty and foam filled crash boxes. From this table, it is concluded that foam-filling of crash box could increase the load efficiency which is desirable when the maximum load value is controlled due to passenger's safety. Specific energy absorption has an increase about $20-22 \%$. These increase in load efficiency and specific energy absorption due to foam-filling structures were reported by some researchers [39, 40, 46, 56, 57]. Furthermore, the value of performance function for foam filled crash box is much higher than empty one that shows better performance of foam filled than empty ones.

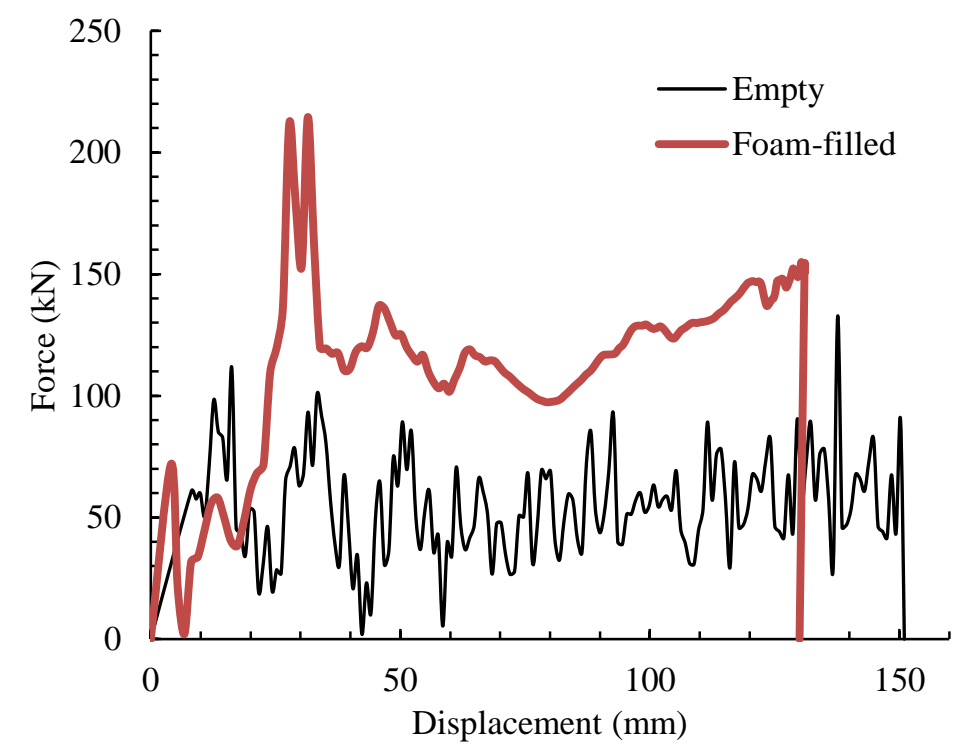

Figure 14. Load-displacement curve of empty and foam-filled crash boxes with tulip triggering.

Table 7. Crashworthiness parameters of an empty and foam-filled crash boxes.

\begin{tabular}{lcccccc}
\hline Foam & $F_{\max }(\mathrm{kN})$ & $F_{\text {mean }}(\mathrm{kN})$ & $\eta$ & $T E A(\mathrm{~kJ})$ & SEA $(\mathrm{J} / \mathrm{g})$ & $\beta$ \\
\hline- & 132.70 & 52.70 & 0.39 & 7.90 & 56.20 & 247.70 \\
\hline EPP & 214.50 & 124.10 & 0.57 & 14.80 & 67.80 & 270.20 \\
\hline
\end{tabular}

\section{CONCLUSION}

In this study, the effects of various parameters such as diameter, thickness, triggering and polymeric foam-filling in a cylindrical crash box were investigated. Three types of triggering, i.e., chamfer, fillet, and tulip are considered. EPP foam with excellent energy absorption and high impact resistance is used for filling the crash box. A new performance parameter is introduced for studying the crashworthiness of a crash box. This parameter considers the effects of the maximum load, mean load, and specific energy absorption. Based on the good agreement between the numerical and experimental results, numerical simulation could determine crash parameters of crash boxes. In general, by increasing the value of the diameter and thickness, the maximum load and the absorbed energy increase. Trigger mechanism increases the load efficiency about $95 \%$. The maximum loads and the energy absorption of all triggered crash boxes are respectively less and higher than the 
crash box without trigger. Triggering dramatically increased the amount of performance function about $144 \%$ for chamfer trigger, $109 \%$ for fillet trigger and $309 \%$ for tulip trigger. Among three simulated triggers, tulip trigger was desirable by reducing the maximum load about $30 \%$ and increasing amount of performance function about $309 \%$. Force efficiency and specific energy absorption of foam-filled crash box increased about $46 \%$ and $20 \%$, respectively, compared to the empty crash box.

\section{REFERENCES}

[1] World Health Organization. Retrieved from https://www.who.int/violence_injury_prevention/road_safety_status/2015; 2015.

[2] Obradovic J, Boria S, Belingardi G. Lightweight design and crash analysis of composite frontal impact energy absorbing structures. Composite Structures 2012; 94(2): 423-430.

[3] Bisagni C. Experimental investigation of the collapse modes and energy absorption characteristics of composite tubes. International Journal of Crashworthiness 2009; 14(4): 365-378.

[4] Jahani M, Beheshti H, Heidari-Rarani M. Crashworthiness of composite and aluminum thin-walled boxes-a numerical study. The 5th International Conference on Composites: Characterization, Fabrication and Application (CCFA-5), 2016.

[5] Teng JG, Hu YM. Behaviour of FRP-jacketed circular steel tubes and cylindrical shells under axial compression, Construction and Building Materials 2007; 21(4): 827-838.

[6] Song HW, Wan ZM, Xie ZM, Du XW. Axial impact behaviour and energy absorption efficiency of composite wrapped metal tubes. International Journal of Impact Engineering 2000; 24 (4): 385-401.

[7] Haedir J, Bambach M, Zhao X, Grzebieta R. Bending strength of CFRPstrengthened circular hollow steel sections. In: 3rd International Conference on FRP Composites in Civil Engineering, 2006.

[8] Haedir J, Bambach M, Zhao X, Grzebieta R. Behaviour of thin-walled CHS beams reinforced by CFRP sheets. In: 4th International Structural Engineering and Construction Conference (ISEC4), Melbourne, Australia, pp. 701-706, 2007.

[9] Doi H. Deformation capacity of circular tubular beam-columns reinforced with CFRP subjected to monotonic loading. Journal of Constructional Steel 2003; 11 : 431-438.

[10] Baroutaji A, Sajjia M, Olabi AG. On the crashworthiness performance of thinwalled energy absorbers: Recent Advances and Future Developments. ThinWalled Structures 2017; 118: 137-163.

[11] Jiao H, Zhao XL. CFRP Strengthened butt-welded Very high strength (VHS) circular steel tubes. Thin-Walled Structures 2004; 42(7): 963-978.

[12] Zhao Y, Gu W, Xu J, Zhang H. The strength of concrete filled CFRP-steel tubes under axial compression. In: 15th International Offshore and Polar Engineering Conference, pp. 19-24, 2005.

[13] Xiao Y, He W, Choi KK. Confined concrete-filled tubular columns. Journal of Structural Engineering 2005; 131(3); 488-497.

[14] Zhao XL, Fernando D, Al-Mahaidi R. CFRP strengthened RHS subjected to transverse end bearing force. Engineering Structures 2006; 28(11)1555-1565. 
[15] Fernando N, Teng J, Yu T, Zhao X. Finite element modelling of CFRP strengthened rectangular steel tubes subjected to end bearing loads. In: AsiaPacific Conference of FRP in Structures, pp. 943-950, 2007.

[16] Reuter C, Troster T. Crashworthiness and numerical simulation of hybrid aluminium-CFRP tubes under axial impact. Thin-Walled Structures 2017; 117: 19.

[17] Wu F, Xiao X, Dong Y, Yang J, Yu Y. Quasi-static axial crush response and energy absorption of layered composite structure formed from novel crochetsintered mesh tube and thin-walled tube. Composite Structures 2018; 192: 592604.

[18] Bambach M, Jama H, Elchalakani M. Axial capacity and design of thin-walled steel SHS strengthened with CFRP. Thin-Walled Structures 2009; 47(10): 11121121.

[19] Abosbaia A, Mahdi E, Hamouda A, Sahari B. Quasi-static axial crushing of segmented and non-segmented composite tubes. Composite Structures 2003; 60(3): 327-343.

[20] Hou T, Pearce G, Prusty B, Kelly D, Thomson R. Pressurised composite tubes as variable load energy absorbers. Composite Structures 2015; 120: 346-357.

[21] Priem C, Othman R, Rozycki P, Guillon D. Experimental investigation of the crash energy absorption of 2.5 D-braided thermoplastic composite tubes. Composite structures 2014; 116: 814-826.

[22] Kim JS, Yoon HJ, Shin KB. A study on crushing behaviours of composite circular tubes with different reinforcing fibres. International Journal of Impact Engineering 2011; 38(4): 198-207.

[23] Ataollahi S, Taher ST, Eshkoor RA, Ariffin AK, Azhari CH. Energy absorption and failure response of silk/epoxy composite square tubes. Experimental. Composites Part B: Engineering 2012; 43(2): 542-548.

[24] Othman A, Abdullah S, Ariffin A, Mohamed N. Investigating the quasi-static axial crushing behaviour of polymeric foam-filled composite pultrusion square tubes. Materials and Design 2014; 63: 446-459.

[25] Eshkoor RA, Oshkovr SA, Sulong AB, Zulkifli R, Ariffin AK, Azhari CH. Comparative research on the crashworthiness characteristics of woven natural silk/epoxy composite tubes. Materials and Design 2013; 47: 248-257.

[26] Eshkoor R, Ude A, Oshkovr S, Sulong AB, Zulkifli R, Ariffin A, Azhari C. Failure mechanism of woven natural silk/epoxy rectangular composite tubes under axial quasi-static crushing test using trigger mechanism. International Journal of Impact Engineering 2014; 64: 53-61.

[27] Elgalai A, Mahdi E, Hamouda A, Sahari B. Crushing response of composite corrugated tubes to quasi-static axial loading. Composite Structures 2004; 66(1): 665-671.

[28] Mahdi E, Sebaey T. Crushing behaviour of hybrid hexagonal/octagonal cellular composite system: aramid/carbon hybrid composite. Materials and Design 2014; 63: 6-13.

[29] Mahdi E, Hamouda A. Energy absorption capability of composite hexagonal ring systems. Materials and Design 2012; 34: 201-210.

[30] Mahdi E, Hamouda A, Sahari B, Khalid Y. Experimental quasi-static axial crushing of cone-tube-cone composite system. Composites Part B: Engineering 2003; 34(3): 285-302. 
[31] Elgalai A, Hamouda A, Mahdi E, Sahari B. Energy absorption capabilities of woven roving glass/epoxy composite tubes: effect of tube length. Strength, Fracture and Complexity 2005; 3(1): 15-24.

[32] Mamalis A, Manolakos D, Ioannidis M, Papapostolou D. Crashworthy characteristics of axially statically compressed thin-walled square CFRP composite tubes: experimental. Composite Structures 2004; 63(3): 347-360.

[33] Palanivelu S, Van Paepegem W, Degrieck J. Crushing and energy absorption performance of different geometrical shapes of small-scale glass/polyester composite tubes under quasi-static loading conditions. Composite Structures 2011; 93: 992-1007.

[34] Zhang Z, Sun W, Zhao Y, Hou S. Crashworthiness of different composite tubes by experiments and simulations. Composites Part B: Engineering 2018; 143: 8695.

[35] Xie S, Yang W, Wang N. Crashworthiness analysis of multi-cell square tubes under axial loads, International Journal of Mechanical Sciences 2017; 121: 106118.

[36] Zhang L, Bai Z, Bai F. Crashworthiness design for bio-inspired multi-cell tubes with quadrilateral, hexagonal and octagonal sections. Thin-Walled Structures 2018; 122: 42-51.

[37] Vinayagar K, Senthil Kumar A. Crashworthiness analysis of double section bitubular thin-walled structures. Thin-Walled Structures 2017; 112: 184-193.

[38] Hussein RD, Ruan D, Lu G. Axial crushing behaviour of honeycomb-filled square carbon fibre reinforced plastic (CFRP) tubes. Composite Structures 2016; 140: 166-179.

[39] Mohammadiha O, Beheshti H, Haji Aboutalebi F. Multi-objective optimization of functionally graded honeycomb filled crash boxes under oblique impact loading. International Journal of Crashworthiness 2015; 20: 44-59.

[40] Gan N, Feng Y, Yin H. Quasi-static axial crushing experiment study of foamfilled CFRP and aluminum alloy thin-walled structures. Composite Structures 2016; 157: 303-319.

[41] Wang L, Liu W, Fang Y. Axial crush behaviour and energy absorption capability of foam-filled GFRP tubes manufactured through vacuum assisted resin infusion process. Thin-Walled Structures 2016; 98: 263-273.

[42] Li Z, Chen R, Lu F. Comparative analysis of crashworthiness of empty and foamfilled thin-walled tubes. Thin-Walled Structures 2018; 124: 343-349.

[43] Chiu LN, Falzon BG, Boman R, Chen B, Yan W. Finite element modelling of composite structures under crushing load. Composite Structures 2015; 131: 215228.

[44] Jahani M, Beheshti H, Heidari-Rarani M, Analytical and numerical investigation of progressive damage in a composite layup. The Biennial International Conference on Experimental Solid Mechanics (X-mech), 2016.

[45] Abaqus CAE 6.14 Documentation User's Manual.

[46] Rajendran R, Prem Sai K, Chandrasekar B. Preliminary investigation of aluminium foam as an energy absorber for nuclear transportation cask. Materials and Design 2008; 29: 1732-1739.

[47] Reyes A, Hopperstad OS, Berstad T. Constitutive modeling of aluminum foam including fracture and statistical variation of density. European Journal of Mechanics 2003; 22: 815-35. 
[48] Ahamd Z, Thambiratnam DP. Numerical optimization of foam-filled conical tubes under axial impact loading. Computers and Structures 2010; 87: 186-197.

[49] Meguid SA, Stranart J, Heyerman J. On the layered micromechanical threedimensional finite element modelling of foam-filled columns. Finite Elements in Analysis and Design 2004; 40: 1035-1057.

[50] Mohammadiha O, Beheshti H. Optimization of functionally graded foam-filled conical tubes under axial impact loading. Journal of Mechanical Science and Technology 2013; 28: 1741-1752.

[51] Sadighi M, Salami S. An investigation on low-velocity impact response of elastomeric and crushable foams. Open Engineering 2012; 2: 627-637.

[52] Mamalis A, Manolakos D, Ioannidis M. Crashworthy characteristics of axially statically compressed thin-walled square CFRP composite tubes: experimental. Composite Structures 2004; 63: 347-360.

[53] Solaimurugan S, Velmurugan R. Influence of fibre orientation and stacking sequence on petalling of glass/polyester composite cylindrical shells under axial compression. International Journal of Solids and Structures 2007; 44: 6999-7020.

[54] Solaimurugan S, Velmurugan R. Progressive crushing of stitched glass/polyester composite cylindrical shells. Composites Science and Technology 2007; 67: 422437.

[55] Jahani M, Beheshti H, Heidari-Rarani M. Effect of different triggering on crashworthiness of composite crash box. Journal of Science and Technology of Composites 2017; 4(3): 327-336.

[56] Duarte I, Krstulović-Opara L, Dias-de-Oliveira J, Vesenjak M. Axial crush performance of polymer-aluminium alloy hybrid foam filled tubes. Thin-Walled Structure 2019; 138: 124-136.

[57] Mahbod M, Asgari M. Energy absorption analysis of a novel foam-filled corrugated composite tube under axial and oblique loadings. Thin-Walled Structure 2018; 129: 58-73. 